\title{
Effect of HBB genotype on survival in a cohort of transfusion-dependent thalassemia patients in Cyprus
}

Haematologica 2021

Volume 106(9):2458-2468

\section{Correspondence:}

PETROS KOUNTOURIS

petrosk@cing.ac.cy

Received: May 25, 2020.

Accepted: July 21, 2020.

Pre-published: July 30, 2020.

https://doi.org/10.3324/haematol.2020.260224

(C)2021 Ferrata Storti Foundation

Material published in Haematologica is covered by copyright. All rights are reserved to the Ferrata Storti Foundation. Use of published material is allowed under the following terms and conditions:

https://creativecommons.org/licenses/by-nc/4.0/legalcode. Copies of published material are allowed for personal or internal use. Sharing published material for non-commercial purposes is subject to the following conditions:

https://creativecommons.org/licenses/by-nc/4.0/legalcode, sect. 3. Reproducing and sharing published material for commercial purposes is not allowed without permission in writing from the publisher.

\section{Petros Kountouris, ${ }^{1,2}$ Kyriaki Michailidou, ${ }^{1,2}$ Soteroula Christou, ${ }^{3}$ Michael Hadjigavriel, ${ }^{4}$ Maria Sitarou, ${ }^{5}$ Anita Kolnagou, ${ }^{6}$ Marina Kleanthous ${ }^{1,2}$ and Paul Telfer ${ }^{7}$}

${ }^{1}$ The Cyprus Institute of Neurology and Genetics, Nicosia, Cyprus; ${ }^{2}$ Cyprus School of Molecular Medicine, Nicosia, Cyprus; ${ }^{3}$ Thalassemia Center, Archbishop Makarios Hospital, Nicosia, Cyprus; ${ }^{4}$ Thalassemia Center, Limassol General Hospital, Limassol, Cyprus; ${ }^{5}$ Thalassemia Center, Larnaca General Hospital, Larnaca, Cyprus; ${ }^{6}$ Thalassemia Center, Paphos General Hospital, Paphos, Cyprus and ${ }^{7}$ Center for Genomics and Child Health, Blizard Institute, Queen Mary University of London, London, UK

\section{ABSTRACT}

I nitiation of regular transfusion in transfusion-dependent thalassemia (TDT) is based on the assessment of clinical phenotype. Pathogenic $H B B$ variants causing $\beta$-thalassemia are important determinants of phenotype and could be used to aid decision-making. We investigated the association of $H B B$ genotype with survival in a cohort study in the four thalassemia centers in Cyprus. $H B B$ genotype was classified as severe $\left(\beta^{0} / \beta^{0}\right.$ or $\left.\beta^{+} / \beta^{0}\right)$, moderate $\left(\beta^{+} / \beta^{+}\right)$, or mild $\left(\beta^{0} / \beta^{++}\right.$or $\left.\beta^{+} / \beta^{++}\right)$. Risk factors for mortality were evaluated using multivariate Cox proportional-hazards regression. Of the 537 subjects who were followed for a total of 20,963 person-years, $80.4 \%$ (95\% confidence interval [95\% CI]: $76.4-$ 84.7) survived to 50 years of age with increasing rates of liver-, infectionand malignancy-related deaths observed during recent follow-up. We evaluated non-modifiable risk factors and found worse outcomes associated with male sex (hazard ratio 1.9, 95\% CI: 1.1-3.0, $P=0.01$ ) and milder genotype (hazard ratio 1.6, 95\% CI: 1.1-2.3, $P=0.02$ ). The effect of genotype was confirmed in a second model, which included treatment effects. Patients with a milder genotype initiated transfusion significantly later and had reduced blood requirements compared to those with moderate or severe genotypes, although pre-transfusion hemoglobin levels did not differ between genotypes. Our results suggest that early treatment decisions to delay transfusion and different long-term treatment strategies in individuals with milder genotypes have led to adverse longterm effects of under-treated thalassemia and worse survival. We propose that $H B B$ genotype determination and use of this information to aid in decision-making can improve long-term outcomes of thalassemia patients.

\section{Introduction}

Standard care of transfusion-dependent thalassemia (TDT) has improved dramatically over the past five decades with the introduction of regular transfusion, a variety of iron-chelating drugs, improved evaluation of transfusion iron overload with magnetic resonance imaging modalities, and the development of specialist centers and regional networks. ${ }^{1-7}$ There has been a consensus on standard care disseminated in national and international guidelines, which are periodically updated, ${ }^{9-10}$ resulting in progressive improvement in survival in successive birth cohorts., ${ }^{2,5-11}$

One aspect of care that is not standardized concerns the decision to start regular transfusion. Individuals at the most severe end of the phenotypic spectrum require regular transfusion before the age of 2 years for survival. At the other end of the spectrum are non-TDT patients who do not require regular transfusion to survive, are less anemic, and have less bone marrow expansion. Clinicians have traditionally avoided 
regular transfusion in these cases because of concerns about the consequences of long-term transfusion, notably transfusion iron overload. The result of not correcting the thalassemia phenotype in earlier life includes a variety of chronic complications which can become apparent later. These include liver disease, pulmonary hypertension, endocrine dysfunction, bone disease and splenomegaly leading to splenectomy. Quality of life is significantly impaired and life expectancy may be reduced. ${ }^{2-15}$ In the middle of the phenotypic spectrum are TDT patients who are not absolutely transfusion-dependent early in their life, and regular transfusion may be delayed in the age range 210 years, ${ }^{16,17}$ during which interval they may be at risk of developing complications of untreated thalassemia.

Over $400 H B B$ variants causing $\beta$-thalassemia have been reported to date ${ }^{18}$ and are generally classified as $\beta^{0}$, in which no functional $\beta$-globin chains can be produced; $\beta^{+}$, in which $\beta$-globin chain production is severely reduced; and $\beta^{++}$, in which $\beta$-globin chain production is mildly reduced. ${ }^{19} \mathrm{~A}$ previous study evaluated the influence of $H B B$ pathogenic variants and other genetic modifiers on time to initiate regular transfusion, and developed a predictive model derived from a composite score. $H B B$ genotype was found to be the most powerful predictor of severity. ${ }^{10,17}$ In routine practice, genetic diagnosis is often not available to the clinician and is not currently used for clinical decision-making. Further evidence of different outcomes associated with different genotypes is needed to recommend routine determination of genotype at birth and to make use of genotypic information in clinical decision-making about the initiation of transfusion and changing other aspects of standard practice.

Cyprus is a Mediterranean island with a relatively stable indigenous population at high risk of thalassemia. Following introduction of a national carrier screening program in 1974, all new diagnoses of infants on the government-controlled southern part of the island have been documented and standard care is given in four treatment centers, ${ }^{20}$ based on shared protocols for transfusion and chelation developed over the past 30 years. The decision on the start of transfusion has been based purely on clinical observation according to best standard practice. The patients have remained stable within each clinic with very little immigration or emigration. The Cyprus thalassemia cohort consists of TDT patients born between 1960 and 2000, and their follow-up to 2004 was published previously. ${ }^{1}$ Herein, we present updated information with longer follow-up from this cohort, in which we generate a more robust estimate of survival of thalassemia with standard treatment, we confirm changing causes of mortality, and we explore the association of genotype with long-term outcomes and survival.

\section{Methods}

\section{Patients and data preparation}

This study is a follow-up of a previously described cohort of patients. ${ }^{1}$ Briefly, we included all patients who were transfusiondependent at the time of the first study, who were born in Cyprus between 1960 and 2000, and who were treated using standard care in the four thalassemia centers. Data were collected and validated for each treatment center up to September 30, 2018. Causes of death were classified as cardiac, liver (including hepatocellular carcinoma), malignancy, infection and other, using standard clinical criteria. Considering the introduction of the Cyprus tha- lassemia screening and prevention program, ${ }^{20}$ which resulted in identification soon after birth of all affected children from 1974 onwards, year of birth was categorized as pre-1974 or 1974 onwards. Based on commonly agreed categories of severity of pathogenic variants, ${ }^{21} H B B$ genotype was classified as severe, moderate and mild, as shown in Table 1, assuming equally spaced severity across categories.

Chelation treatment was categorized based on the predominant chelator used during follow-up from year 2000 onwards: (i) deferoxamine only, (ii) deferiprone alone or in combination with deferoxamine, and (iii) deferasirox. Deferoxamine was given by subcutaneous or intravenous infusion, whereas deferiprone and deferasirox were administered orally. For splenectomy, the effect on survival was assumed to be dependent on whether and when it had been performed, and was categorized as (i) before 16 years of age, and (ii) after 16 years of age or not done.

To evaluate genotype associations with the transfusion regimens, we used data previously collected for 336 patients from the cohort, as part of the THALAMOSS project. ${ }^{22}$ These data comprised the age of the first regular transfusion, and annual blood usage and pre-transfusion hemoglobin levels, between 2014 and 2016.

\section{Statistical analysis}

A univariate analysis was performed to estimate the overall survival and the association of different risk factors with mortality using Kaplan-Meier analysis. The log-rank test was used to evaluate the statistical significance of the effect of the risk factors on survival. For the multivariate analysis, we used Cox proportionalhazards regression with a backwards approach in which all potential factors that were significant in the univariate analysis were included in the initial regression model and then sequentially removed to obtain the best-fit model. All models were tested for whether they met the proportional hazards assumption for a Cox proportional-hazards model.

Proportions were compared in contingency tables using the Pearson $\chi^{2}$ test. Mortality rates and confidence intervals were calculated overall and for the periods 1980-89, 1990-99, 2000-09, and 2010-18. The Kruskal-Wallis test and the Wilcoxon rank-sum test for post-hoc analyses were utilized to study the association between $H B B$ genotype and transfusion data. All statistical analyses were performed using $R$ (version 3.6.1) and $R$ packages survival and survminer.

\section{Ethical considerations}

The study was approved by the Cyprus National Bioethics Committee and was initiated by PT as part of a project commissioned by the Cyprus Ministry of Health. Subsequently, informed consent was obtained for clinical follow-up of the cohort as part of the THALAMOSS project (EU FP7 grant agreement 306201), which included collection of transfusion data.

\section{Results}

A summary of the clinical characteristics of the 537 cohort patients are documented in Table 2. There were two fewer patients than in the original study. Both of these patients were found to have been ineligible, one because of birth prior to 1960 , and the other with a diagnosis of $\mathrm{Hb} \mathrm{H}$ disease. Eight patients had been treated with sibling allogeneic stem cell transplant, at a mean age of 12.7 years. Follow-up on these eight patients was censored at the date of transplantation.

The total number of patient-years of follow up was 
Table 1. Pathogenic HBB variations in the cohort of thalassemia-dependent thalassemia patients.

\begin{tabular}{|c|c|c|c|c|}
\hline Allele 1 & Allele 2 & Allele phenotypes & Cenotype category & Number (\%) \\
\hline IVS I-110 G>A & IVS I-1 G>A & $\beta^{+} / \beta^{0}$ & Severe & $48(9.4)$ \\
\hline IVS I-110 G>A & CD $39 \mathrm{CAG}>\mathrm{TAG}$ & $\beta^{+} / \beta^{0}$ & Severe & $23(4.5)$ \\
\hline IVS I-1 G>A & IVS II-745 C>C & $\beta^{0} / \beta^{+}$ & Severe & $5(1.0)$ \\
\hline IVS $\mathrm{I}-1 \mathrm{G}>\mathrm{A}$ & IVS I-1 G>A & $\beta^{0} / \beta^{0}$ & Severe & $2(0.4)$ \\
\hline IVS I-1 G>A & CD $44-C$ & $\beta^{0} \beta^{0}$ & Severe & $2(0.4)$ \\
\hline IVS I-110 G>A & IVS II-1 G>A & $\beta^{+} / \beta^{0}$ & Severe & $2(0.4)$ \\
\hline IVS I-110 G>A & CD 44 -C & $\beta^{+} / \beta^{0}$ & Severe & $1(0.2)$ \\
\hline IVS I-110 G>A & CD 5 -CT & $\beta^{+} / \beta^{0}$ & Severe & $1(0.2)$ \\
\hline IVS II-745 C>G & CD 39 CAG>TAG & $\beta^{+} / \beta^{0}$ & Severe & $1(0.2)$ \\
\hline IVS I-110 G $>A$ & IVS I-110 G>A & $\beta^{+} / \beta^{+}$ & Moderate & $306(59.8)$ \\
\hline IVS I-110 G>A & IVS II-745 C>G & $\beta^{+} / \beta^{+}$ & Moderate & $29(5.7)$ \\
\hline IVS I-110 G $>A$ & IVS II-848 C>A & $\beta^{+} / \beta^{+}$ & Moderate & $1(0.2)$ \\
\hline IVS II-745 C>C & IVS II-745 C>G & $\beta+/ \beta^{+}$ & Moderate & $1(0.2)$ \\
\hline IVS I-110 G>A & IVS I-6 T>C & $\beta^{+} / \beta^{++}$ & Mild & $81(15.8)$ \\
\hline IVS II-745 C>C & IVS I-6 T>C & $\beta^{+} / \beta^{++}$ & Mild & $4(0.8)$ \\
\hline IVS I-110 G>A & Hb Knossos & $\beta^{+} / \beta^{++}$ & Mild & $1(0.2)$ \\
\hline IVS I-110 G>A & $-87 \mathrm{C}>\mathrm{G}$ & $\beta^{+} / \beta^{++}$ & Mild & $1(0.2)$ \\
\hline IVS I-1 G>A & IVS I-6 T>C & $\beta^{0} / \beta^{++}$ & Mild & $1(0.2)$ \\
\hline IVS I-6 T>C & CD 39 CAG > TAG & $\beta^{++} / \beta^{0}$ & Mild & $1(0.2)$ \\
\hline $\mathrm{CD} 39 \mathrm{CAG}>\mathrm{TAG}$ & Hb Lepore Boston-Washington & $\beta^{0} / \beta^{++}$ & Mild & $1(0.2)$ \\
\hline Total & & & & 512 \\
\hline
\end{tabular}

20,963. The majority of the patients were born between 1960 and 1979 (453 patients, 84.4\%). Splenectomy status was significantly associated with clinic $(P=0.02)$, with $21.8 \%$ of patients splenectomized during childhood in Nicosia, compared to $36.7 \%, 29.3 \%$ and $34.9 \%$ in, respectively, Larnaca, Limassol and Paphos, while there was no significant difference in choice of iron chelation therapy between clinics. Thirty-eight (7.1\%) patients had evidence of hepatitis $\mathrm{C}$ infection (HCV antibody positive), of whom $9(1.7 \%)$ were HCV RNA positive at the end of the study and $29(7.3 \%)$ were HCV RNA negative. Three patients $(0.6 \%)$ were positive for hepatitis B surface antigen.

A summary of the genotypes of the study patients is shown in Table 1. HBB genotype data were not available for 24 patients, who had died before genotyping was introduced in Cyprus. An additional patient was removed from the genotype analysis because thalassemia was caused by $\alpha$-locus duplications co-inherited with $\beta$-thalassemia trait. ${ }^{23}$ Homozygous IVS I-110 G>A $\left(\beta^{+}\right)$was the commonest genotype $(59.8 \%)$ and there was a large proportion of patients with a combination of IVS I-110 G>A $\left(\beta^{+}\right)$and IVS I-6 T $>C\left(\beta^{++}\right)$. There was a significant trend on performing splenectomy in childhood with decreasing severity of genotype, specifically $19 \%$ in the severe genotype group, $27.8 \%$ in the moderate genotype group, and $38.1 \%$ in the mild genotype group $(P=0.02)$. There was also a significant trend across the genotypic spectrum in chelation therapy, with increasing proportions of patients with a milder phenotype remaining on deferoxamine rather than switching to oral chelation, specifically $14.3 \%$ with severe genotype, $17.5 \%$ with moderate genotype; and $28.9 \%$ with mild genotype $(P=0.02)$. Genotyping for the $\alpha$-globin locus and the XmnI $\mathrm{C} / \mathrm{T}$ polymorphism was almost complete for the study population $(92.4 \%$ and $89.4 \%$, respectively). The XmnI T allele, which is associated with increased $\mathrm{Hb}$ F production, has a low prevalence and, thus, limited influence on clinical outcomes in the study population. In contrast, $\alpha^{+}$-thalassemia trait is present in about $19 \%$ of the population, whereas the prevalence of $\alpha^{0}$-thalassemia trait is lower $(1.6 \%)^{24}$

\section{Mortality rates and causes of death}

By September 2018, 94 (17.5\%) patients had died. Crude comparisons of proportions are shown in Table 2, indicating that survival was significantly associated with sex, splenectomy in childhood, and receiving oral chelation compared to those chelated primarily with deferoxamine. However, 44 of $70(57.1 \%)$ of the patients who received deferoxamine chelation died before the year 2000, and these patients would not have had the opportunity to receive prolonged oral chelation. Those with more severe $H B B$ genotypes were also more likely to survive $(P=0.03$ for trend). The mean age of death in the severe genotype category was higher (39.2 years, $95 \%$ confidence interval $[95 \%$ $\mathrm{CI}]$ : 28.4-50.1) than in the moderate (mean age $31.4,95 \%$ CI: $28.3-34.4)$ and mild (35.0 years, 95\% CI: $30.0-40.1)$ genotype categories. There were no significant differences in proportions surviving or not surviving with different $\alpha$-globin gene numbers or with the XmnI polymorphism.

Causes of death are shown in Table 3. The ten deaths caused by liver disease included six cases of liver failure and four cases of hepatocellular carcinoma. Other malignancies comprised acute myeloid leukemia ( $n=2)$, T-cell lymphoma $(n=1)$, metastatic melanoma $(n=1)$, renal carcinoma $(n=1)$, carcinoma of colon $(n=1)$, carcinoma of skull $(n=1)$. Other causes of death were categorized as not known $(n=7)$, accident $(n=5)$, stroke $(n=2)$, hypoglycemia $(n=1)$, myasthenia $(\mathrm{n}=1)$, acute graft-versus-host disease $(\mathrm{n}=1)$, and pulmonary hypertension $(n=1)$. Table 3 also shows mortality rates per 10,000 patient-years from different causes during sequential 


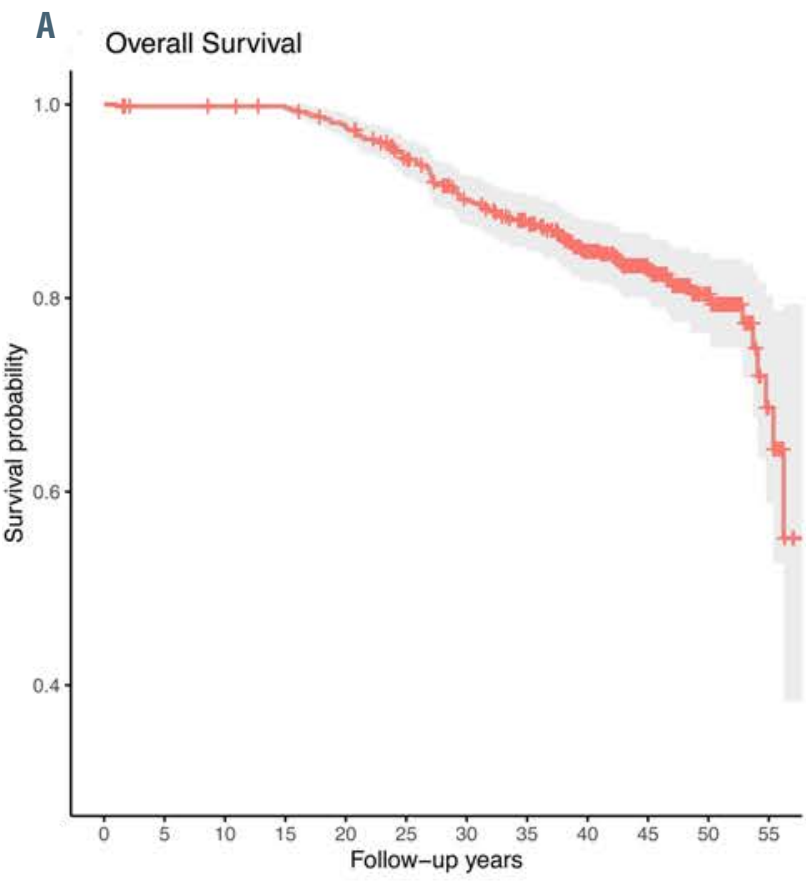

Number at risk

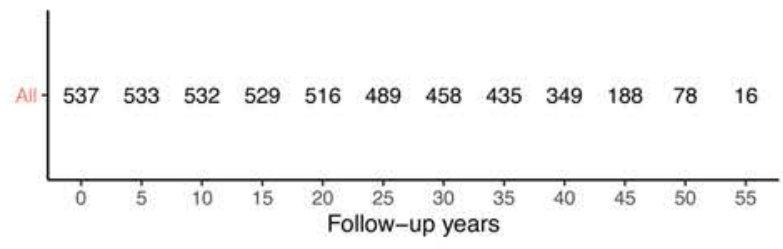

$H B B$ genotype

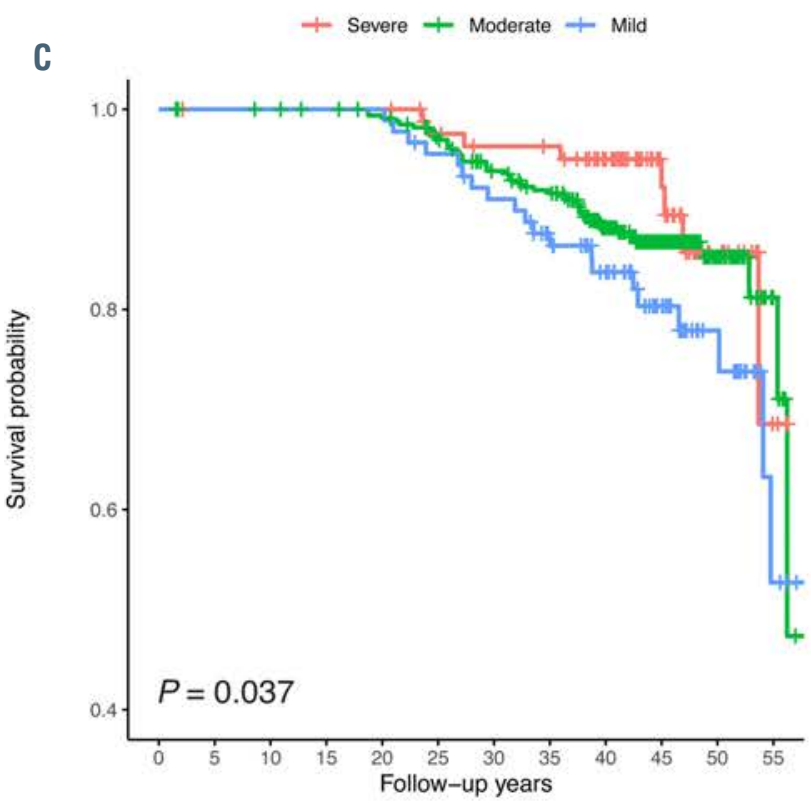

Number at risk

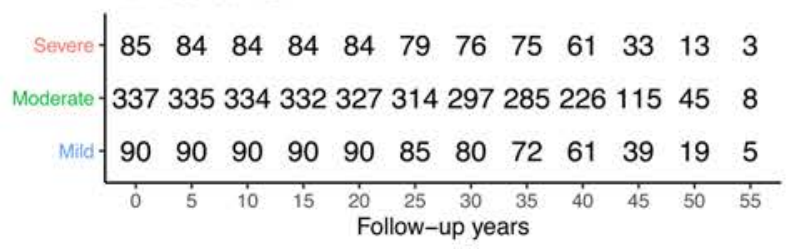

B

Sex

$$
+ \text { Female }+ \text { Male }
$$

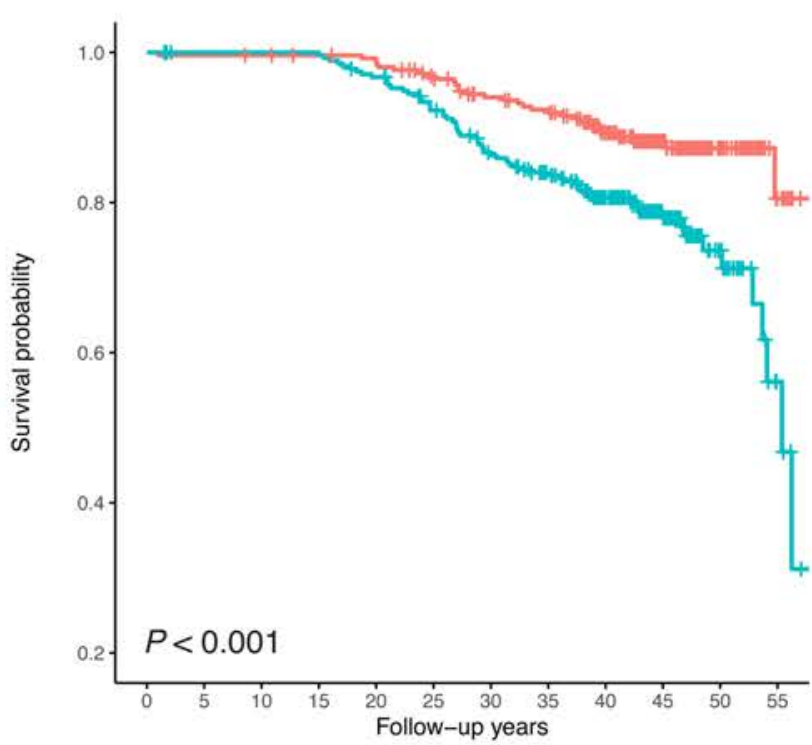

Number at risk

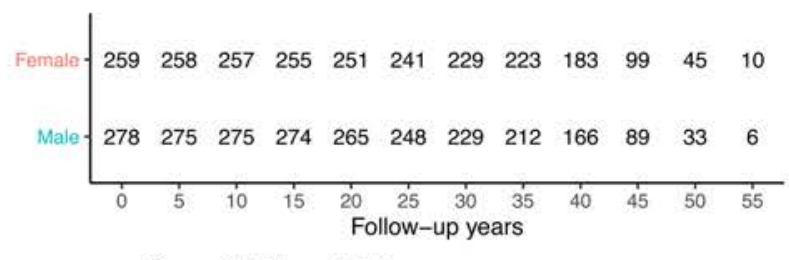

Year of birth $\geq 1974$

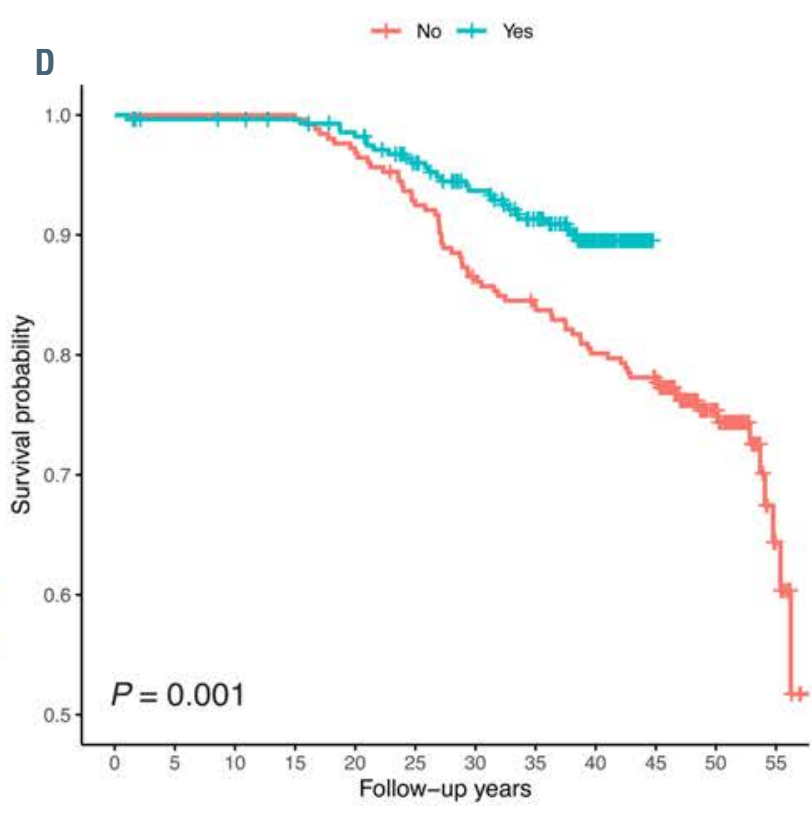

Number at risk

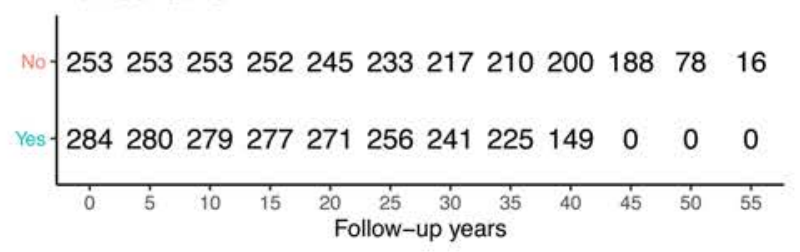


Table 2. Demographic and clinical features of the cohort of patients.

\begin{tabular}{|c|c|c|c|c|}
\hline & $\begin{array}{c}\text { Alive } \\
N=443(\%)\end{array}$ & $\begin{array}{c}\text { Died } \\
N=94(\%)\end{array}$ & $\begin{array}{l}\text { Total } \\
N=537\end{array}$ & $\begin{array}{c}\text { Comparison of proportion } \\
\text { alive and died }(P)\end{array}$ \\
\hline $\begin{array}{l}\text { Sex } \\
\text { Male } \\
\text { Female }\end{array}$ & $\begin{array}{l}214(77.0) \\
229(88.4)\end{array}$ & $\begin{array}{l}64(23.0) \\
30(11.6)\end{array}$ & $\begin{array}{l}278 \\
259\end{array}$ & $\chi^{2}=11.4,1$ d.f., $P<0.001$ \\
\hline $\begin{array}{l}\text { Year of birth } \\
<1974 \\
\geq 1974\end{array}$ & $\begin{array}{l}186(73.5) \\
257(90.5)\end{array}$ & $\begin{array}{l}67(26.5) \\
27(9.5)\end{array}$ & $\begin{array}{l}253 \\
284\end{array}$ & $x^{2}=25.5 .1$ d.f... $P<0.001$ \\
\hline $\begin{array}{l}\text { Age, at end of study period } \\
\text { or death (years, mean, SD) }\end{array}$ & $43.1(8.1)$ & $30.4(11.0)$ & & \\
\hline $\begin{array}{l}\text { Clinic } \\
\text { Larnaca } \\
\text { Limassol } \\
\text { Nicosia } \\
\text { Paphos }\end{array}$ & $\begin{array}{l}99(81.8) \\
115(82.1) \\
186(81.2) \\
43(91.5)\end{array}$ & $\begin{array}{c}22(18.2) \\
25(17.9) \\
43(18.8) \\
4(8.5)\end{array}$ & $\begin{array}{c}121 \\
140 \\
229 \\
47\end{array}$ & $\chi^{2}=2.9,3$ d.f., $P=0.401$ \\
\hline $\begin{array}{l}H B B \text { genotype } \\
\text { Severe } \\
\text { Moderate } \\
\text { Mild } \\
\text { Not known }\end{array}$ & $\begin{array}{c}77(90.6) \\
293(86.9) \\
70(77.8) \\
2(8.3)\end{array}$ & $\begin{array}{c}8(9.4) \\
44(13.1) \\
20(22.2) \\
22(91.7)\end{array}$ & $\begin{array}{c}85 \\
337 \\
90 \\
24\end{array}$ & $\chi^{2}=6.8,2$ d.f., $P=0.0341$ \\
\hline $\begin{array}{l}\alpha \text {-globin gene number } \\
1 \\
2 \\
3 \\
4 \\
5 \\
6 \\
\text { Not known }\end{array}$ & $\begin{array}{c}2(100) \\
14(93.3) \\
84(89.4) \\
328(86.5) \\
2(100) \\
1(100) \\
12(27.3)\end{array}$ & $\begin{array}{c}0(0) \\
1(6.7) \\
10(10.6) \\
51(13.5) \\
0(0) \\
0(0) \\
32(72.7)\end{array}$ & $\begin{array}{c}2 \\
15 \\
94 \\
379 \\
2 \\
1 \\
44\end{array}$ & $\chi^{2}=1.8,5$ d.f., $P=0.8781$ \\
\hline $\begin{array}{l}\text { XmnI polymorphism } \\
\text { CC } \\
\text { CT } \\
\text { Not known }\end{array}$ & $\begin{array}{c}407(88.3) \\
19(100) \\
17(29.8)\end{array}$ & $\begin{array}{l}54(11.7) \\
0(0) \\
40(70.2)\end{array}$ & $\begin{array}{c}461 \\
19 \\
57\end{array}$ & $\chi^{2}=1.5,1$ d.f., $P=0.2251$ \\
\hline $\begin{array}{l}\text { Splenectomy } \\
\text { Childhood } \\
\text { Adulthood or not splenectomised } \\
\text { Not known }\end{array}$ & $\begin{array}{c}108(74.5) \\
334(91.0) \\
1(4.2)\end{array}$ & $\begin{array}{l}37(25.5) \\
33(9.0) \\
24(95.8)\end{array}$ & $\begin{array}{l}145 \\
367 \\
25\end{array}$ & $\chi^{2}=22.7,1$ d.f., $P<0.001^{\text {a }}$ \\
\hline $\begin{array}{l}\text { Iron chelation therapy } \\
\text { DFO only } \\
\text { DFO switched to DFP-containing } \\
\text { DFO switched to DFX }\end{array}$ & $\begin{array}{c}52(42.6) \\
311(93.7) \\
80(96.4)\end{array}$ & $\begin{array}{c}70(57.4) \\
21(6.3) \\
3(3.6)\end{array}$ & $\begin{array}{c}122 \\
332 \\
83\end{array}$ & $\chi^{2}=176,2$ d.f., $P<0.001$ \\
\hline
\end{tabular}

${ }^{a}$ Analysis restricted to the population in which the variable was known. ${ }^{\mathrm{b}}$ One patient was removed from the genotype analysis because thalassemia was caused by $\alpha$-locus duplications co-inherited with $\beta$-thalassemia trait. ${ }^{23}$ d.f.: degrees of freedom; SD: standard deviation; DFO: deferoxamine; DFP: deferiprone; DFX: deferasirox.

time periods of follow-up. There was a lower incidence of overall mortality in the period 1980-89, but no significant differences in mortality rates in subsequent time periods and no overall trend. There was a significant decrease in cardiac mortality over the last three time periods, and an increased incidence of deaths due to liver disease, cancer and infections during successive decades. However, there were insufficient numbers of deaths from these causes in each individual decade for a statistical analysis. The proportion of deaths due to heart disease was lower in those with a mild genotype ( 6 out of $20,30 \%$ ) than in those with moderate (23 out of $44,52 \%$ ) and severe ( 4 out of $8,50 \%$ ) genotypes. These differences did not reach statistical significance. Of the 15 subjects who died due to infectious causes, six of nine with known splenectomy status had been splenectomized. Five of $94(5.3 \%)$ patients who died were HCV RNA positive at the time of death. Three of these died of heart failure and two from liver disease. HCV infection could be a contributing factor for these deaths, but was likely to be the primary cause in only two $(2.1 \%)$ cases.

\section{Survival analysis}

We constructed two models to explore risk factors associated with mortality. In both models, data were right-censored on September 30, 2018, at death or bone marrow transplantation. In the first model, we considered the entire follow-up period and evaluated non-modifiable risk factors. These comprised sex, year of birth, treatment clinic and genotype. To assess the impact of treatment factors (iron chelation therapy and splenectomy), a second model was constructed. This took into account the licensing of the oral iron chelator deferiprone in 1999 and general availability for prescription from 2000. Deferiprone was sometimes used as single therapy and frequently in combination with deferoxamine, depending on the clinician's assessment of iron overload severity. A second oral chelator, deferasirox was licensed and available for prescription in 2006 and there was switching between different chelator regimes over time after 2006 to optimize therapy for each individual. Since it would be biased to compare chelator efficacy during the period 
Table 3. Incidence rates for mortality by cause and period of follow-up.

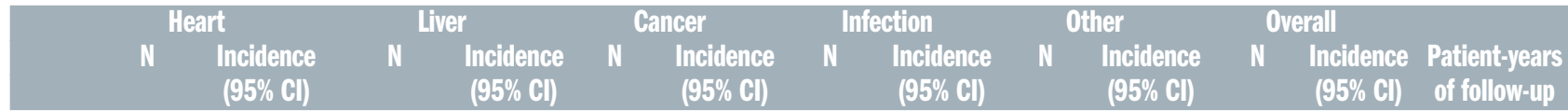

\begin{tabular}{|c|c|c|c|c|c|c|c|c|c|c|c|c|}
\hline 1980-1989 & 4 & $7.5(2.8-20.1)$ & 1 & $1.9(0.27-13.3)$ & 0 & 0.00 & 2 & $3.77(0.9-15.0)$ & 4 & $7.5(2.8-20.1)$ & $1120.7(11.5-37.4)$ & $5,310.7$ \\
\hline 1990-1999 & 21 & $41.3(26.9-63.3)$ & 2 & 3.9 & 0 & 0.00 & 4 & $7.9(3.0-20.9)$ & 6 & $11.8(5.3-26.2)$ & 3364.9 (46.2-91.2) & $5,085.7$ \\
\hline 2000-2009 & 13 & $27.4(15.9-47.1)$ & 2 & $4.2(1.1-16.8)$ & 3 & $6.3(2.0-19.6)$ & 4 & $8.4(3.2-22.4)$ & 4 & $8.4(3.2-22.4)$ & $2654.8(37.3-80.3)$ & $4,747.9$ \\
\hline 2010-2018 & 6 & $15.3(6.9-34.1)$ & 5 & $12.8(5.3-30.7)$ & 4 & $10.2(3.8-27.2)$ & 5 & $12.8(5.3-30.7)$ & 4 & $10.2(3.8-27.2)$ & 2461.3 (41.1-91.3) & $3,915.8$ \\
\hline $1980-2018$ & 44 & $23.1(17.2-31.0)$ & 10 & $5.3(2.0-8.5)$ & 7 & $3.7(1.0-6.4)$ & 15 & $7.9(4.7-13.1)$ & 18 & $9.4(6.0-15.0)$ & $9449.3(40.3-60.3)$ & $19,060.0$ \\
\hline
\end{tabular}

Incidence presented as events per 10,000 patient-years; $95 \%$ CI: $95 \%$ confidence interval.

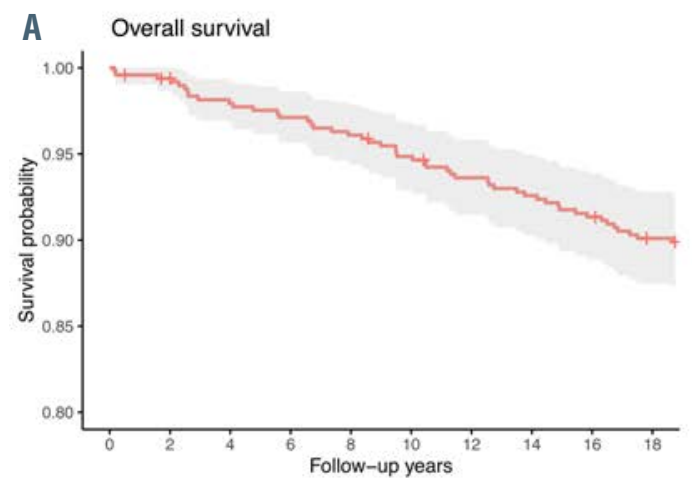

Number at risk

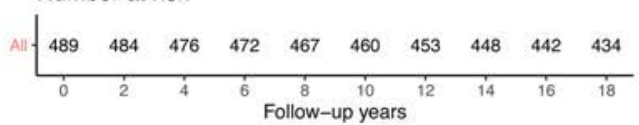

C

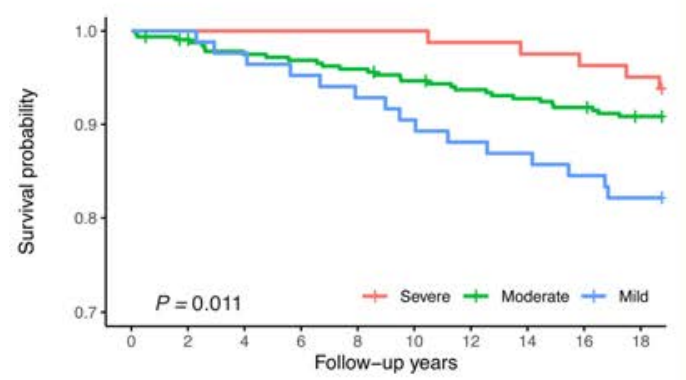

Number at risk \begin{tabular}{c|cccccccccc} 
Severe & 81 & 81 & 81 & 81 & 81 & 81 & 80 & 79 & 78 & 77 \\
Moderate & 321 & 316 & 310 & 308 & 305 & 300 & 296 & 293 & 290 & 285
\end{tabular}

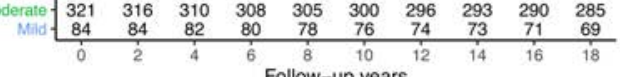

E

Splenectomy in childhood

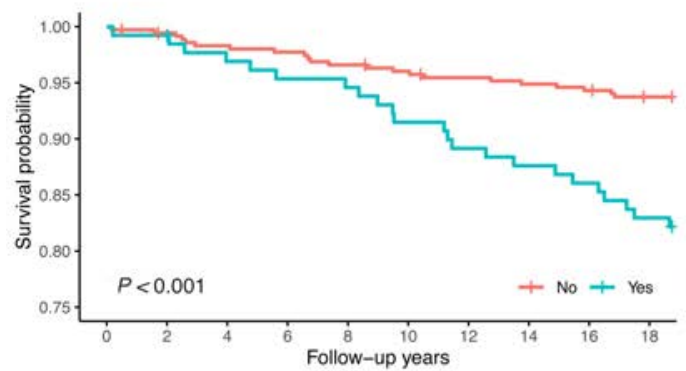

Number at risk

Nof $\begin{array}{llllllllll}354 & 350 & 346 & 344 & 340 & 337 & 334 & 332 & 330 & 326\end{array}$

Yes. \begin{tabular}{cccccccccc}
130 & 129 & 125 & 123 & 122 & 118 & 115 & 113 & 111 & 107 \\
\hline$\dot{0}$ & $\dot{2}$ & $\dot{4}$ & $\dot{6}$ & $\dot{8}$ & 10 & 12 & 14 & 16 & 18
\end{tabular}
B Sex

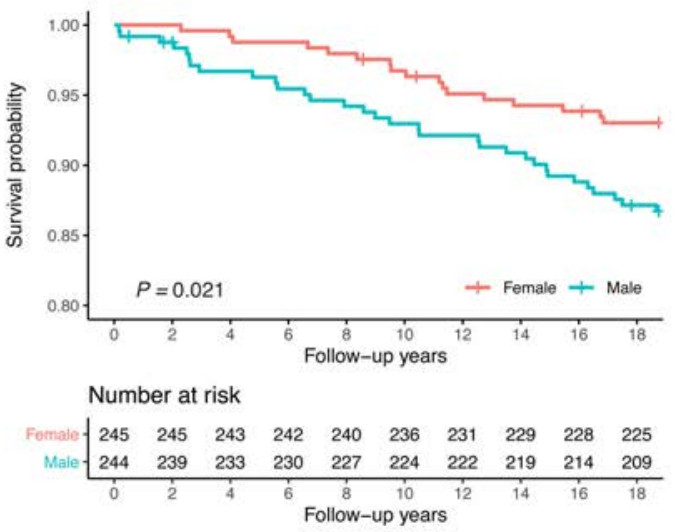

Dear of birth $\geq 1974$

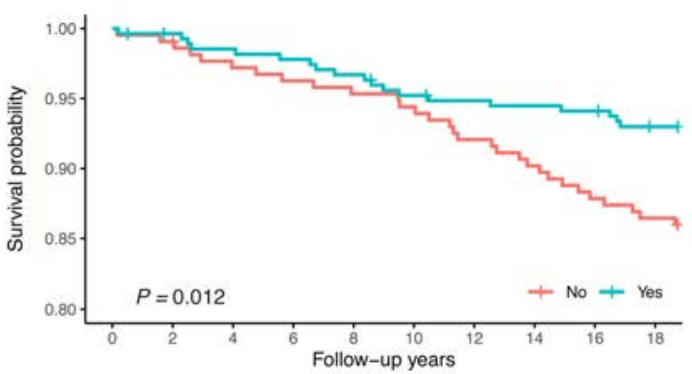

Number at risk

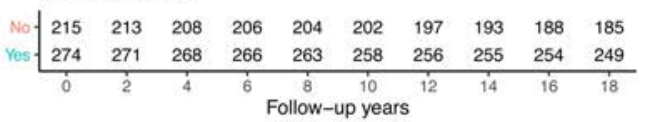

$\mathrm{F}$

Chelation

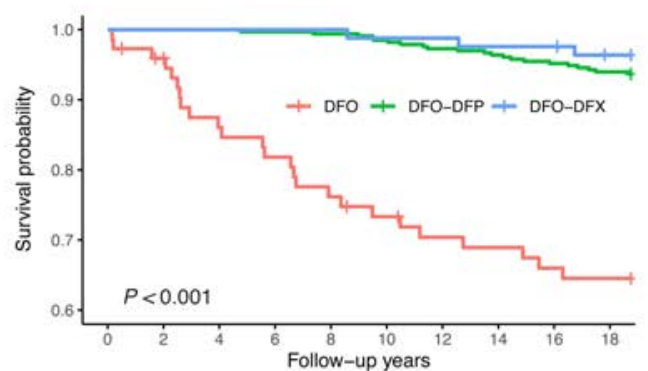

Number at risk

\begin{tabular}{c|cccccccccc} 
DFO & 74 & 69 & 61 & 58 & 54 & 51 & 48 & 47 & 45 & 44 \\
DFO-DFP & 332 & 332 & 332 & 331 & 330 & 327 & 323 & 320 & 316 & 312 \\
\hline
\end{tabular}

DFO-DFX. \begin{tabular}{cccccccccc}
332 & 332 & 332 & 331 & 330 & 327 & 323 & 320 & 316 & 312 \\
83 & 83 & 83 & 83 & 83 & 82 & 82 & 81 & 81 & 78 \\
\hline$\dot{0}$ & $\dot{2}$ & $\dot{4}$ & $\dot{6}$ & $\dot{8}$ & 10 & 12 & 14 & 16 & 18
\end{tabular}
Figure 2. KaplanMeier curves for survival during follow-up 2000 to 2018 showing the effects of risk factors with statistically significant effects in univariate analysis. (A) Surviva of the overall cohort, and categorized by (B) sex, (C) HBB genotype, (D) year of birth, (E) splenectomy during childhood, and (F) type of chelation therapy. DFO: deferoxamine; DFP: deferiprone; DFX: deferasirox. 
Table 4. Univariate and multivariate analysis of risk factors for survival in the primary analysis.

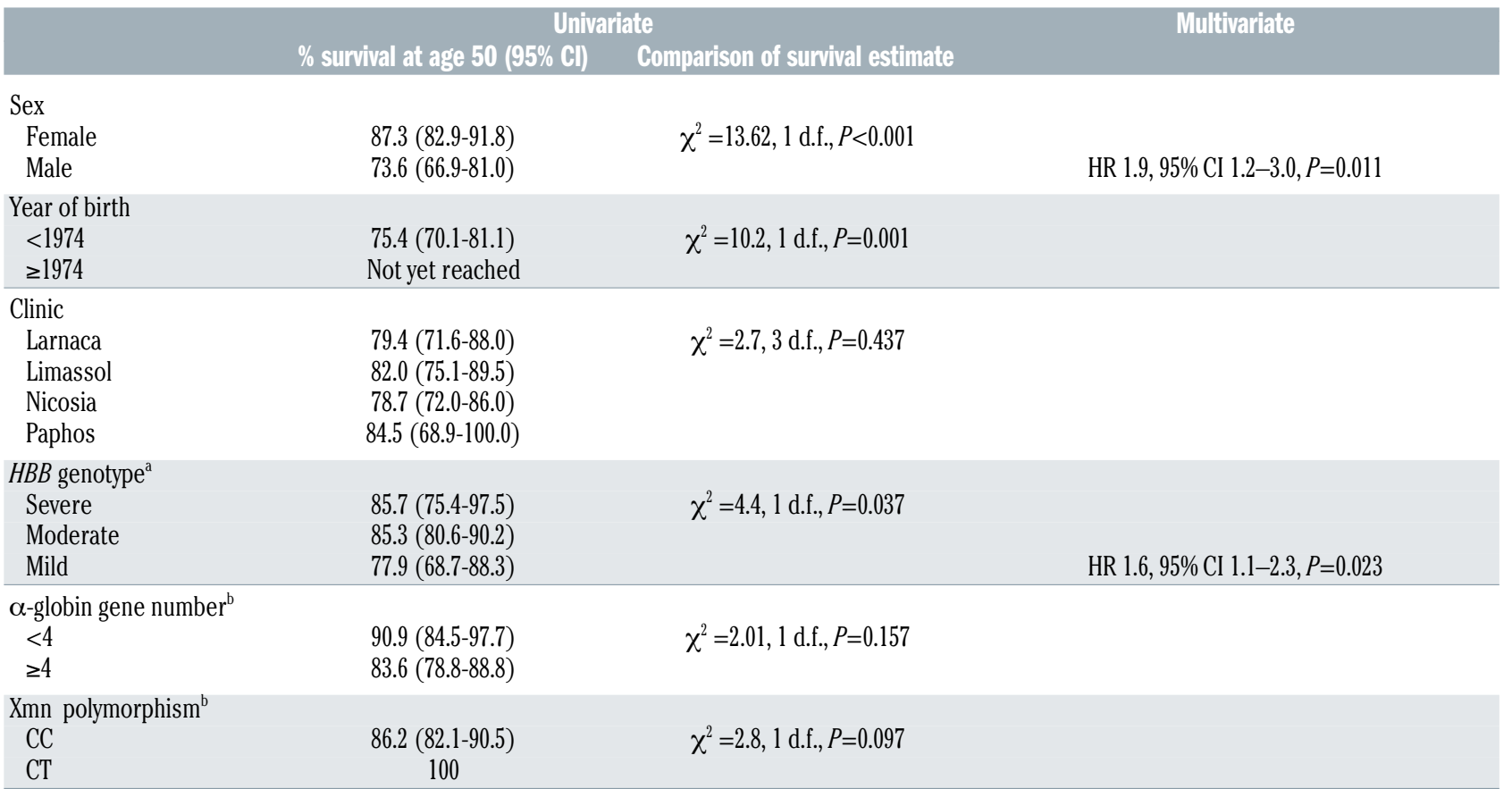

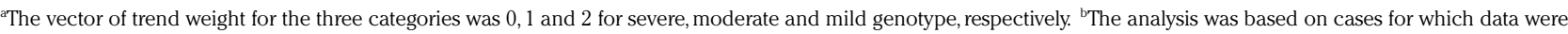
available (see Table 2 for missing data). d.f.: degrees of freedom; $95 \%$ CI: $95 \%$ confidence interval, HR: hazard ratio.

1980-2000, when the only option available was deferoxamine, follow-up was restricted to the period 2000-2018, when at least one option for oral chelation was available, and data were left-truncated at January 1, 2000.

The results of the survival analysis are shown in Table 4 and Figure 1 . Survival by age 50 was estimated at $80.4 \%$ (95\% CI: 76.4-84.7). In the first model of survival, univariate analysis showed that male sex, milder $H B B$ genotype and birth before 1974 were significantly associated with worse survival, while there was no significant effect of treatment clinic, $\alpha$-globin gene number or XmnI polymorphism. When the survival analysis was applied separately to cardiac and non-cardiac deaths, the genotype had no significant effect on cardiac deaths, but a significant effect on non-cardiac deaths $(P=0.02)$. In the multivariate model, independent predictors of survival were male sex (hazard ratio [HR] 1.9, 95\% CI: 1.2-3.0, $P=0.01$ ) and genotype, with each decrement in severity being associated with a 1.6-fold increased risk of mortality (HR 1.6, 95\% CI: 1.1-2.3, $P=0.02$ ).

In the second model, 489 evaluable patients were followed for a total of 8,644 person-years. The estimated survival rate was $89.9 \%$ (95\% CI: 87.3-92.6) as of September 30, 2018. Univariate and multivariate analyses of risk factors for survival over this time period are shown in Table 5 and Figure 2. In the univariate analysis, male sex, birth before 1974, milder genotype, splenectomy in childhood and deferoxamine-only chelation treatment were significantly associated with worse survival, with iron chelation treatment being the most significant factor. In multivariate analysis, the best-fit model included chelation, sex, splenectomy in childhood and $H B B$ genotype. Importantly, the significant effects of male sex and milder genotype on survival were confirmed in the second multivariate model, while deferoxamine-only treatment and splenectomy in childhood were also associated with worse survival.

\section{Association of genotype with transfusion parameters}

Transfusion data were available for 336 patients of the cohort $(62.6 \%)$ and were used to evaluate possible associations between $H B B$ genotype and the transfusion regimens. The mean age of first regular transfusion was 29.4 months, the mean transfusion frequency per year was 28.7 times, the mean blood volume transfused was $179 \mathrm{~mL} / \mathrm{kg} / \mathrm{year}$ and the mean pre-transfusion hemoglobin level was 9.9 $\mathrm{g} / \mathrm{dL}$.

The $H B B$ genotype was significantly associated with age at first regular transfusion $(P=0.001)$, annual transfusion frequency $(P=0.04)$ and blood volume transfused $(P=0.01)$, whereas no association was found for pre-transfusion hemoglobin levels $(P=0.8)$.

Post-hoc statistical analysis was subsequently performed to demonstrate differences in transfusion between different genotypic severity groups, shown in Figure 3. Statistically significant differences were identified between the severe and mild groups for age at first transfusion $(P=0.004)$ and annual transfusion frequency $(P=0.024)$. In addition, statistically significant differences were found between the moderate and mild groups for age at first regular transfusion $(P=0.0006)$, annual transfusion frequency $(P=0.025)$ and blood volume transfused $(P=0.003)$. The was not a significant association between the severe and moderate groups for any of the transfusion parameters studied.

\section{Discussion}

The first report on this cohort was right-censored at December 31, 2004. ${ }^{1}$ The current data cut-off allows a further 14 years of follow-up, and more robust estimates of overall survival, trends in mortality and risk factors for mortality.

In a study of health outcomes and healthcare costs in the $\mathrm{UK},{ }^{11}$ survival of thalassemia patients treated according to 

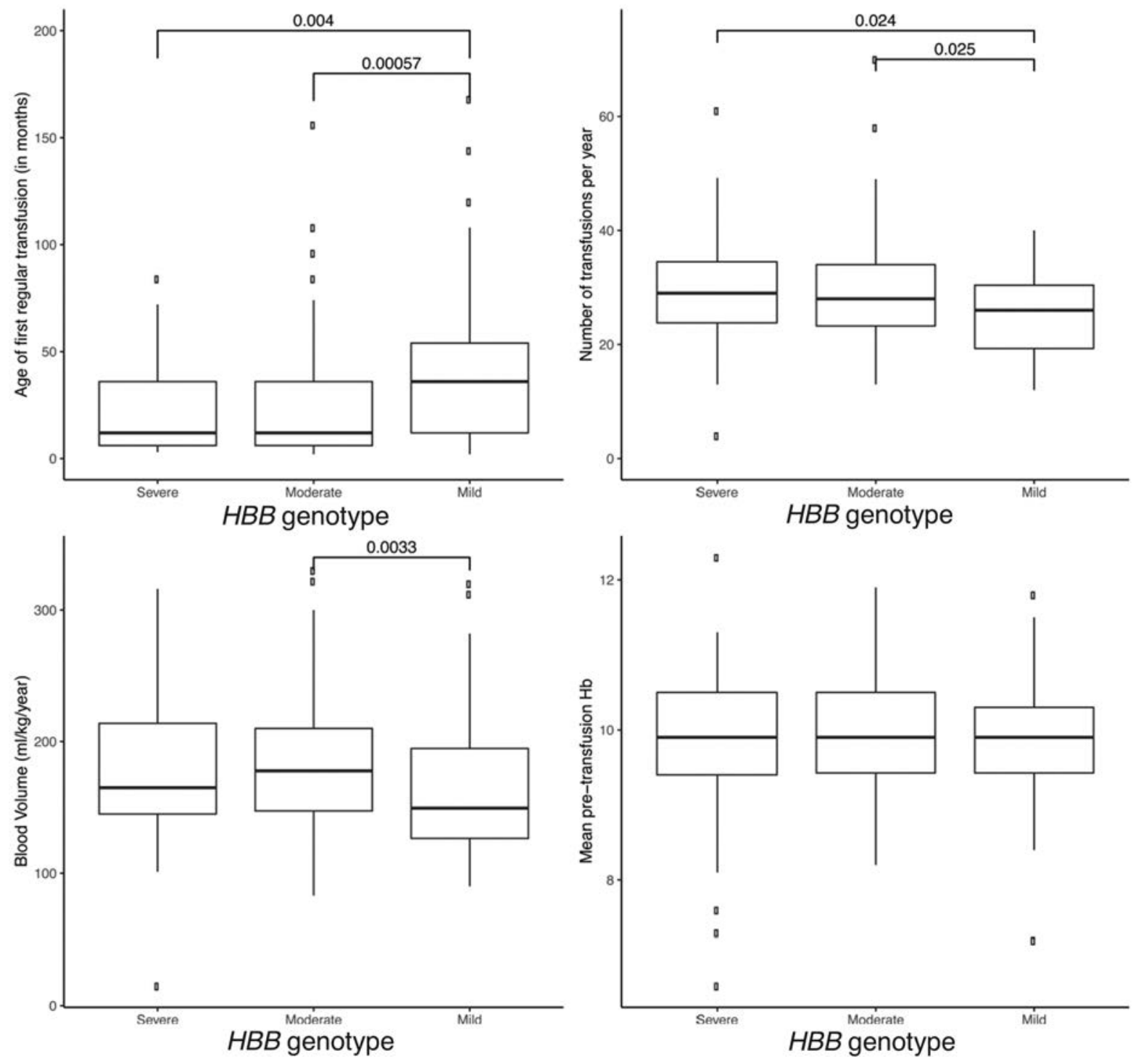

Figure 3. Boxplots illustrating the distribution of transfusion data among groups with HBB genotypes of different severity. Statistically significant associations, determined with the Wilcoxon rank-sum non-parametric test, are shown.

standard guidelines was forward-estimated at $63 \%$ by the age of 50 years. This was based on a review of available data in which clinical follow-up was only reported up to 30 years of age. The estimate of $80.4 \%$ in this study is more robust and significantly more optimistic. Life expectancy in the general population of Cyprus has been reported recently using national statistics over the period 1986-2012. ${ }^{25}$ About $90-95 \%$ are expected to survive to 50 years, and our data would suggest that a diagnosis of thalassemia reduces the percentage surviving to this age by about $15 \%$. These data should be helpful in discussing outcomes of thalassemia with new parents, in refining health economic models, comparing outcomes of new therapies with standard care, and in making treatment decisions about use of alternative donor transplantation, where overall survival with unrelated, or mismatched family donors are currently less than $80 \%{ }^{26}$

Causes of death appear to be changing with longer term follow-up of TDT patients. We have confirmed reduction in deaths due to cardiac causes over the past 20 years, as reported previously in this cohort ${ }^{1}$ and in other studies. ${ }^{5} \mathrm{We}$ also noted increasing mortality related to liver disease and infection in this cohort, a finding that has also been reported in recent registry studies from Sicily and Greece. ${ }^{6,27}$ The increasing numbers of deaths due to malignancies has also been noted previously. ${ }^{28}$ Although the incidence of cancer naturally increases with age, and it has not been established that the incidence is significantly different from that in the general population, the types of malignancy appear to be different, notably with a higher representation of hepatocellular carcinoma. Further follow-up of the cohort and evaluation in other similar studies will be needed to confirm this finding.

The distribution of $H B B$ genotypes in this study is consistent with the known distribution of thalassemia alleles in the Cypriot population. ${ }^{29,30}$ There is a predominance of homozygosity for IVS I-110 G>A, a severe $\beta^{+}$variant causing a cryptic splice site in the first intron of $H B B$ which reduces functional $\beta$-globin mRNA to about $20 \%$ of normal. ${ }^{31}$ Next in prevalence is IVS 1-6 T $>C$, causing aberrant splicing at the first intronic junction of $H B B$, with a less severe reduction in $\beta$-globin mRNA. Being a milder variant, it has been classified as $\beta^{++}$or $\beta^{+}$in different studies. We have selected the former annotation for this study. ${ }^{21}$ The 
Table 5. Univariate and multivariate analysis of risk factors for survival in the secondary analysis.

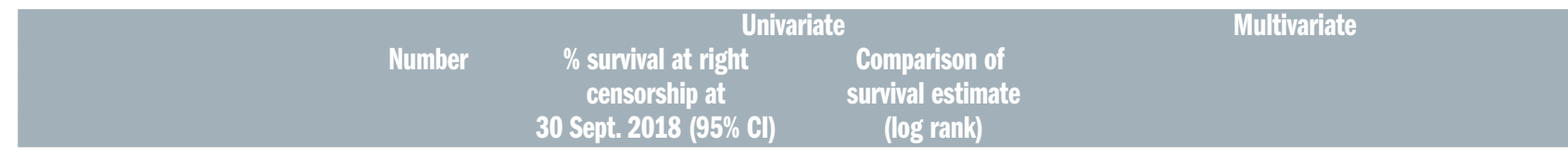

Sex

\begin{tabular}{|c|c|c|c|c|}
\hline $\begin{array}{l}\text { Female } \\
\text { Male }\end{array}$ & $\begin{array}{l}245 \\
244\end{array}$ & $\begin{array}{l}93.0(89.9-96.3) \\
86.7(82.6-91.1)\end{array}$ & $\chi^{2}=5.3,1$ d.f., $P=0.021$ & HR 2.34, 95\% CI 1.26-4.34, $P=0.007$ \\
\hline $\begin{array}{l}\text { Year of birth } \\
<1974 \\
\geq 1974\end{array}$ & $\begin{array}{l}215 \\
274\end{array}$ & $\begin{array}{l}86.0(81.5-90.8) \\
93.0(90.0-96.1)\end{array}$ & $\chi^{2}=6.3,1$ d.f., $P=0.012$ & \\
\hline
\end{tabular}

Clinic

\begin{tabular}{|c|c|c|c|}
\hline Larnaca & 107 & $90.3(84.8-96.2)$ & $\chi^{2}=2.0,3$ d.f., $P=0.578$ \\
\hline Limassol & 128 & $89.0(83.7-94.6)$ & \\
\hline Nicosia & 209 & $89.0(84.9-93.3)$ & \\
\hline Paphos & 45 & $95.6(89.7-100)$ & \\
\hline
\end{tabular}

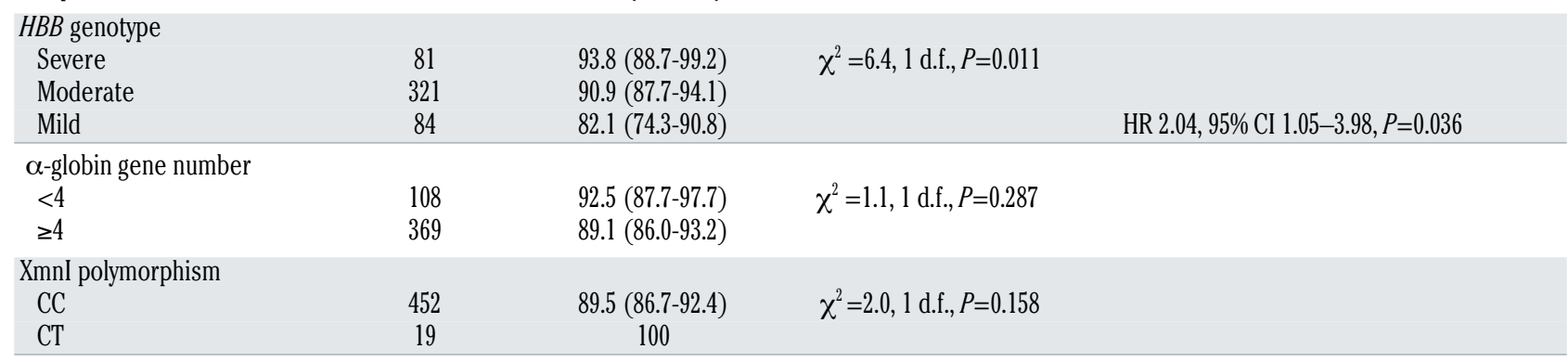

Iron chelation

$\begin{array}{lccc}\text { DFO only } & 74 & 64.5(54.2-76.8) & \chi^{2}=75.1,2 \text { d.f., } P<0.001 \\ \text { DFO switched to DFP-containing } & 332 & 93.7(91.1-96.3)\end{array}$

DFO switched to DFX $\quad 83 \quad 96.4(92.4-100)$

HR $0.10,95 \%$ CI $0.05-0.19, P<0.001$

HR $0.08,95 \%$ CI $0.025-0.028, P<0.001$

Splenectomy
Childhood $\quad 130 \quad 82.2(75.8-89.1) \quad \chi^{2}=14.7,1$ d.f., $P<0.001 \quad$ HR $7.92,95 \%$ CI $2.03-30.75, P=0.003$

Adulthood or not splenectomized $\quad 354 \quad 93.7$ (91.2-96.3)

d.f.: degrees of freedom; $95 \%$ CI: 95\% confidence interval, HR: hazard ratio: DFO: deferoxamine; DFP: deferiprone; DFX: deferasirox.

most severe category $\left(\beta^{0} / \beta^{0}\right)$ is rare in the Cypriot TDT population $(0.8 \%)$, and this contrasts with some other TDT populations, such as in Sardinia where $92 \%$ of TDT patients have homozygous or compound heterozygous $\beta^{0}$ mutations. ${ }^{16}$ Nevertheless, the two commonest variants in this cohort are common in the Mediterranean and the Middle East, and are also observed in many immigrant populations ${ }^{18}$ For risk factor analysis, we introduced a genotypic severity categorization, with the assumption that severity increases linearly across the spectrum mild/ moderate/severe. This categorization could be explored in studies of severity, treatment and outcomes in other populations, even if the specific variants are different.

The variability of risk factors during follow-up creates problems for the statistical modeling. We addressed this by evaluating two different models, the first of which incorporated only non-modifiable factors and did not include treatment factors, but assumed that standard care was applied uniformly to all subjects. The worse survival associated with male sex had been previously reported $\mathrm{d}^{1,2}$ and could be linked to worse adherence to the recommended chelation therapy and a higher prevalence of specific complications, such as heart disease, in male patients. Moreover, the significantly worse survival associated with milder $H B B$ genotype would suggest that standard care is not sufficiently effective to cancel the pathological effects of milder genotype. One recent confirmatory study has shown a convergence in mortality in a population of thalassemia major and thalassemia intermedia patients in Sicily with similar length of follow-up. ${ }^{27}$ The definition of thalassemia intermedia in the study from Sicily was regular transfusion after the age of 2 years. Based on the transfusion data of the current study, the above definition of thalassemia intermedia encompasses $44.4 \%$ (122 out of 275) of patients with moderate or mild genotypes in the Cyprus TDT patient cohort.

The second model, which included treatment effects, confirmed that male sex and milder $H B B$ genotype were significantly associated with mortality. Here, chelation therapy for each individual was categorized according to the predominant agent used. We confirmed that oral iron chelation therapy had a strong independent protective effect on survival compared to continuing with deferoxamine therapy. The positive effect on survival of switching from deferoxamine- to deferiprone-containing therapy has been previously reported from this cohort and in other studies. ${ }^{3,32}$ The survival benefit of deferasirox compared to deferoxamine has not previously been reported, and may be related to improved adherence to an oral rather than injected agent and its once-daily administration. It is important to note that the categorization of chelation therapy is a simplification, and the assumptions of the Cox proportional-hazards model are not fully met with regard to chelation. Therefore, the significant protective effects observed in this study should be interpreted with caution.

We did not have comprehensive data on other genetic modifiers, ${ }^{33}$ while some genotype data were missing, particularly $\alpha$-globin genotype $(44 / 537,8.2 \%)$ and $\mathrm{XmnI}$ polymorphism (57/537, 10.6\%). However, the prevalence of 
severity-alleviating factors, such as $\alpha^{0}$ deletions and minor allele of the XmnI polymorphism, is low in this population and is unlikely to have affected the overall analysis of survival. In contrast, $H B B$ genotype appears to be a significant determinant of severity, a finding confirmed in a study of likelihood of initiation of transfusion in patients with $\beta$-thalassemia, in whom transfusion was 30 times more likely in those with a severe genotype than in those with a mild genotype. ${ }^{15,16}$ The effect of genotype on survival could potentially be biased due to deaths of patients with severe genotypes at an earlier age and exclusion of patients who died early in the follow-up, before genotyping was introduced in Cyprus. Nevertheless, this is unlikely to have a major influence on our conclusions, because there was no significant difference between genotype frequencies and age at death in patients with available genotypes, while the year of birth was used in a multivariate survival analysis (data not shown) without materially changing the significant effect of genotype on survival.

Survival in TDT is associated with a variety of risk factors, not all of which are quantifiable, and these risk factors are likely to differ according to the cause of mortality. The cause of mortality appears to be changing from cardiac iron overload to other etiologies more closely associated with the long-term effects of inadequate suppression of the underlying thalassemia phenotype. Our results suggest that $H B B$ genotype could affect mortality through its causative effect on disease phenotype, which is now more apparent because of the reduction of cardiac deaths. The analysis of transfusion data shows that patients with mild genotypes are beginning transfusion significantly later in life and require less blood. However, once started on transfusion, there is no difference in pre-transfusion hemoglobin level between the genotypes, indicating that lower volumes of blood are required to suppress ineffective erythropoiesis in the group with mild genotypes. These observations in this study suggest that the delay in starting transfusion, along with the long-term transfusion strategy, are likely to have a negative impact on the survival of patients with mild genotypes. Notably, current treatment guidelines for TDT recommend that the decision about starting transfusion is based on clinical assessment. Our results suggest that determining the $H B B$ geno- type and using this information to aid in decision-making could improve long-term outcomes.

The effect of genotype on mortality could be examined in other previously described thalassemia cohorts ${ }^{2,6,7}$ and in combined datasets, thus allowing the study of a more diverse spectrum of genotypes. This is a future direction of our work. If confirmed, the effect of genotype could have significant implications for the management of TDT. Firstly, it would provide evidence that patients diagnosed with $\beta$-thalassemia should initiate regular transfusion early, using a transfusion regimen which effectively suppresses erythropoiesis, to avoid long-term complications of uncontrolled anemia and marrow expansion. Secondly, it would contribute to the decision of whether to institute emerging strategies for treating TDT including enhancement of endogenous erythropoiesis, ${ }^{34}$ as well as lentiviral and gene editing strategies, ${ }^{35,36}$ both of which appear to be more effective in patients with milder genotypes and higher residual globin chain production.

\section{Disclosures}

PT was principal investigator in a phase III study of luspatercept, a product of Celgene Corporation; he has received research funding from and participated in advisory boards for Bluebird Bio, Inc; and has participated in advisory boards for Novartis and Apopharma.

\section{Contributions}

$P K, M K$ and PT designed the study protocol, and wrote and edited the manuscript; $S C, M H, M S$ and $A K$ managed the patients according to national and international guidelines and collected clinical data; $P K$ and $M K$ performed the DNA studies; $P K$, $K M$ and $P T$ performed the statistical analysis.

\section{Acknowledgments}

We wish to thank the Cypriot patients and families attending the Greek Cypriot thalassemia clinics and the staff in these centers who have provided dedicated, long-term care over the study period.

\section{Funding}

This work was partially funded by the THALAMOSS project (FP7-HEALTH-2012-INNOVATION-1: grant agreement 306201).

\section{References}

1. Telfer P, Coen PG, Christou S, et al. Survival of medically treated thalassemia patients in Cyprus. Trends and risk factors over the period 1980-2004. Haematologica. 2006; 91(9):1187-1192.

2. Borgna-Pignatti C, Rugolotto S, De Stefano $\mathrm{P}$, et al. Survival and complications in patients with thalassemia major treated with transfusion and deferoxamine. Haematologica. 2004;89(10):1187-1193.

3. Borgna-Pignatti C, Cappellini MD, De Stefano P, et al. Cardiac morbidity and mortality in deferoxamine- or deferiprone-treated patients with thalassemia major. Blood. 2006;107(9):3733-3737.

4. Modell B, Khan M, Darlison M, et al. A national register for surveillance of inherited disorders: beta thalassaemia in the United Kingdom. Bull World Health Organ. 2001; 79(11):1006-1013.

5. Modell B, Khan M, Darlison M, Westwood $\mathrm{MA}$, Ingram D, Pennell DJ. Improved survival of thalassaemia major in the UK and relation to $2^{*}$ cardiovascular magnetic resonance. J Cardiovasc Magn Reson. 2008; 10:42.

6. Voskaridou E, Kattamis A, Fragodimitri C, et al. National registry of hemoglobinopathies in Greece: updated demographics, current trends in affected births, and causes of mortality. Ann Hematol. 2019;98(1):55-66.

7. Ladis V, Chouliaras G, Berdoukas V, et al. Relation of chelation regimes to cardiac mortality and morbidity in patients with thalassaemia major: an observational study from a large Greek Unit. Eur J Haematol. 2010;85(4):335-344

8. UK Thalassaemia Society. Standards for the Clinical Care of Children and Adults with Thalassaemia in the UK, 3rd Edition. 2016.

9. Cappellini MD, Cohen A, Porter J, Taher A, Viprakasit V, eds. Guidelines for the Management of Transfusion Dependent Thalassaemia (TDT). Thalassaemia International Federation. 2014

10. Musallam KM, Angastiniotis M, Eleftheriou A, Porter JB. Cross-talk between available guidelines for the man- agement of patients with beta-thalassemia major. Acta Haematol. 2013;130(2):64-73.

11. Weidlich D, Kefalas P, Guest JF. Healthcare costs and outcomes of managing beta-thalassemia major over 50 years in the United Kingdom. Transfusion. 2016;56(5):10381045.

12. Cappellini MD, Porter JB, Musallam KM, et al. Development of a new disease severity scoring system for patients with non-transfusion-dependent thalassemia. Eur J Intern Med. 2016;28:91-96.

13. Ratip S, Skuse D, Porter J, Wonke B, Yardumian A, Modell B. Psychosocial and clinical burden of thalassaemia intermedia and its implications for prenatal diagnosis. Arch Dis Child. 1995;72(5):408-412.

14. Cappellini MD, Kattamis A, Viprakasit V, et al. Quality of life in patients with beta-thalassemia: a prospective study of transfusiondependent and non-transfusion-dependent patients in Greece, Italy, Lebanon, and Thailand. Am J Hematol. 2019;94(10):E261E264

15. Cappellini MD, Musallam KM, Taher AT. 
Insight onto the pathophysiology and clinical complications of thalassemia intermedia. Hemoglobin. 2009;33(Suppl 1):S145-159.

16. Danjou F, Anni F, Perseu L, et al. Genetic modifiers of $\beta$-thalassemia and clinical severity as assessed by age at first transfusion. Haematologica. 2012;97(7):989-993.

17. Danjou F, Francavilla M, Anni F, et al. A genetic score for the prediction of beta-thalassemia severity. Haematologica. 2015; 100(4):452-457.

18. Kountouris P, Lederer CW, Fanis P, Feleki X, Old J, Kleanthous M. IthaGenes: an interactive database for haemoglobin variations and epidemiology. PLoS One. 2014; 9(7):e103020.

19. Thein SL. Molecular basis of beta thalassemia and potential therapeutic targets. Blood Cells Mol Dis. 2018;70:54-65.

20. Angastiniotis MA, Hadjiminas MG. Prevention of thalassaemia in Cyprus. Lancet. 1981:1(8216):369-371.

21. Thein SL. The molecular basis of beta-thalassemia. Cold Spring Harb Perspect Med. 2013;3(5):a011700

22. [No authors listed] Thalassemia Modular Stratification System for personalized therapy of beta-thalassemia (THALAMOSS). Hum Gene Ther Clin Dev. 2015;26(2):100102.

23. Clark B, Shooter C, Smith F, et al. Beta thalassaemia intermedia due to co-inheritance of three unique alpha globin cluster duplica- tions characterised by next generation sequencing analysis. Br J Haematol. 2018; 180(1):160-164.

24. Kyriacou K, Kyrri A, Kalogirou E, et al. Hb Bart's levels in cord blood and alpha-thalassemia mutations in Cyprus. Hemoglobin. 2000;24(3):171-180.

25. Agathokleous MN, Nena E, Chadolias D, et al. Estimating life expectancy of the population in Cyprus with the use of life tables. Hippokratia. 2016;20(2):99-103.

26. Baronciani D, Angelucci E, Potschger U, et al. Hemopoietic stem cell transplantation in thalassemia: a report from the European Society for Blood and Bone Marrow Transplantation Hemoglobinopathy Registry, 2000-2010. Bone Marrow Transplant. 2016;51(4):536-541.

27. Vitrano A, Calvaruso G, Lai E, et al. The era of comparable life expectancy between thalassaemia major and intermedia: Is it time to revisit the major-intermedia dichotomy? $\mathrm{Br}$ J Haematol. 2017;176(1):124-130.

28. Zanella S, Garani MC, Borgna-Pignatti C. Malignancies and thalassemia: a review of the literature. Ann N Y Acad Sci. 2016; 1368(1):140-148.

29. Baysal E, Indrak K, Bozkurt G, et al. The beta-thalassaemia mutations in the population of Cyprus. Br J Haematol. 1992; 81(4):607-609.

30. Kountouris P, Kousiappa I, Papasavva T, et al. The molecular spectrum and distribution of haemoglobinopathies in Cyprus: a 20year retrospective study. Sci Rep. 2016; 6:26371.

31. Spritz RA, Jagadeeswaran P, Choudary PV, et al. Base substitution in an intervening sequence of a beta+-thalassemic human globin gene. Proc Natl Acad Sci U S A. 1981; 78(4):2455-2459.

32. Telfer PT, Warburton F, Christou S, et al. Improved survival in thalassemia major patients on switching from desferrioxamine to combined chelation therapy with desferrioxamine and deferiprone. Haematologica. 2009;94(12):1777-1778

33. Stephanou C, Tamana S, Minaidou A Papasavva P, Kleanthous M, Kountouris P. Genetic modifiers at the crossroads of personalised medicine for haemoglo binopathies. J Clin Med. 2019;8(11):1927.

34. Piga A, Perrotta S, Gamberini MR, et al. Luspatercept improves hemoglobin levels and blood transfusion requirements in a study of patients with beta-thalassemia. Blood. 2019;133(12):1279-1289.

35. Thompson AA, Walters MC, Kwiatkowsk $\mathrm{J}$, et al. Gene therapy in patients with transfusion-dependent beta-thalassemia. $\mathrm{N}$ Engl Med. 2018;378(16):1479-1493.

36. Magrin E, Miccio A, Cavazzana M Lentiviral and genome-editing strategies for the treatment of beta-hemoglobinopathies. Blood. 2019;134(15):1203-1213. 